\title{
The Influential Image of Nighttime Urban Public Park in Forming Place Identity
}

\author{
Mohd Riduan Ngesan ${ }^{1}$, Hafazah Abdul Karim², Syed Sobri Zubir ${ }^{3}$ \\ ${ }^{1}$ Centre for Environment-Behaviour Studies \\ 1,2 Centre for Town and Regional Planning Studies \\ ${ }^{3}$ Centre for Architecture Studies \\ Faculty of Architecture, Planning \& Surveying \\ Universiti Teknologi MARA, Shah Alam 40450, Malaysia \\ nightcityconcept@gmail.com
}

\begin{abstract}
The design of urban public park is an important factor which influence urban community leisure. The objective of this study is to investigate the community perceptions on nighttime leisure activities in urban public park. The questionnaire survey is done in Padang (green field) located in the urban center of Shah Alam and Putrajaya using random stratifies technique. There are four types of variable studied related to nighttime leisure in an urban public park namely comforts, conveniences, safety and nighttime leisure. The findings from this study are expected to show a positive perception of nighttime leisure in urban public park towards urban community.
\end{abstract}

Keywords: Image; urban public park; place identity; nighttime leisure activities

eISSN 2514-751X C 2018. The Authors. Published for AMER ABRA cE-Bs by e-International Publishing House, Ltd., UK. This is an open-access article under the CC BY-NC-ND license (http://creativecommons.org/licenses/bync-nd/4.0/). Peer-review under responsibility of AMER (Association of Malaysian Environment-Behaviour Researchers), ABRA (Association of Behavioural Researchers on Asians) and cE-Bs (Centre for EnvironmentBehaviour Studies), Faculty of Architecture, Planning \& Surveying, Universiti Teknologi MARA, Malaysia.

DOI: https://doi.org/10.21834/aje-bs.v5i18.55 


\subsection{Introduction}

Urban parks fulfill a variety of social and psychological needs of the residents. Thus, the success in fulfilling the social functions by urban public parks may be measured by the frequency of the visitation by the population for whom they were designed. However, the hot climate during the day due to the effect of global warming discouraged human activities in an urban park (Ewert, 1991). Moreover, Shaharudin et al. (2010) argued that urban 'heat island' significantly reduced livability and human comfort where it is extremely hot to conduct outdoor activities during daytime. Furthermore the busy lifestyle of urbanites also affects the lack of time for leisure and recreation activities in urban outdoor spaces (Oguz and Cakci, 2010). These constraints have changed the behavioral patterns of the urban communities where people prefer to carry out their leisure activities in outdoor public-park after the sun has set (Ngesan and Karim, 2012). Cheshmehzangi (2012) argued that, public realm could appear in many ways comprising varied identity of place. In this respect, public realm does not have a certain identity but rather is fulfilled with several changing identities influenced by content (person or object) and context (culture or environment) where content is the inherent value (Relph, 1976).

\subsection{Literature Review}

Place identity could best be understood as that which makes a place unique. It is not just the identity of a place that is important, but also the identity that a person or group has with that place (Relph, 1976). Proshansky et. al (1983), defined place-identity as a "pot-pourri of memories, conceptions, interpretations, ideas, and related feelings about specific physical settings, as well as types of settings". Place identity changes occur throughout a person's lifetime. It is a substructure of self-identity and is comprised of perceptions and comprehensions regarding the environment. These perceptions and conceptions can be organized into two types of clusters; one type consists of memories, thoughts, values and settings, and the second type consists of the relationship among different settings of place (Proshansky \& Fabian, 1987). Place identity theory does not provide much detail regarding the structure and process (Twigger-Ross et. al, 2003), but refers to "schemata" that Neisser (1976) describe as perceptions and ideas that also concern the physical environment. Moreover, the perspectives on place have gone from 'physical determinism' where the environment was seen as having direct effects on behaviour (Franck, 1984), to the view of the people-environment relation as dynamic and interactive. Akin to this, Wicker (1979) also emphasizes that behaviour settings are social constructs developed over time. This will include if the place is experienced during nighttime. It definitely offers a different environment and experience of place throughout the whole day (Zaki and Ngesan, 2012). Currently, many nightlife activities are focus on tourists/ visitor such as pubs, bars, concerts and others that disturb the urban community during nighttime (Ngesan and Karim, 2011).

Understanding a place comes from visibility and creation of place as an image. Places may have become imageable on their own but what makes them associated with others is the awareness of signage and symbolism. It is forms understanding of a place, however, do not become meaningful merely because of their visibility. Moreover, past memories and 
relations with particular elements can also establish a signage and symbolism system in mind. Signage itself is one of the most generalised ways in which identity of an environment is recognised. As it is elucidated by Walmsley (1988), social categories or in another words behavioural values 'rest on shared [and collective] meanings and that meanings are systems of signs'. Within the urban environment, this is a very important factor. Akin to this, Lynch (1960) also emphasised upon the importance of nodes and landmarks as ways of enhancing legibility and identity of a place. As part of this theory, we can clarify that a building for instance can both be material and/or characteristics of an urban environment. Accordingly, Walmsley (1988) asserted that buildings in general are considered as a signage system. In this respect, both buildings and urban environments can appear as symbolic entities or landmarks. Symbolism itself is a trendy approach in urban design in order to make a place identifiable and distinctive. To Cooper (1974), there are four kinds of symbolism that could also be acknowledged in continuous stages of symbolism. The first kind is the 'archetypal symbolism', which is the collective or global kind of symbolism. The second type is the 'associational symbolism', whereby a place or element may become symbolic through 'associations based on direct personal experience....[that]... is a very private affair...[and]... is beyond the control of environmental designers'. The third type is the 'acculturated symbolism', which is merely attached to the association; but from a cultural origin rather than the personal attachment. The fourth kind is the 'symbolism of the familiar', based on our everyday visual and experience that to symbolise security and continuity'.

\subsection{Methodology}

The purpose of this study is to investigate the reliability of urban public park image in relation to nighttime place identity through findings from the pilot survey. Shah Alam's urban public park located in the city center of Section 14 has been chosen as a case study area due to its subdued urban nature: - a well provided community facilities; and the lack of nighttime commercial and entertainment centres. The urban public park that will consider for this study is a green field of urban park. It is an open area covered by grass and lighted up at night.

The background study was conducted to gather information and findings from previous researches regarding the image of place identity. Besides, the researcher also had carry out an observation survey in Shah Alam's urban public park. The results served very well in formulating the attributes and items for images domain in the pilot survey of questionnaire as an assessment tool to measure the reliability of images of urban public park during nighttime. The strategy chosen for the research design was based on a pilot survey which required 30 samples of respondents. According to Thomas (2004), the sample size for pilot survey is within 10 to 30 sample of respondent which depend on the complexity of the study. The respondents are required to state their perception item on the image of urban public park during nighttime which influence them to carry out leisure activities. To answer the questionnaire, the respondents are required to state their preference of priority on a rating Likert scale of 1 to 7 ; where 1 represent as very poor, 2 represent as poor, 3 represent slightly poor, 4 represent as moderate, 5 represent as slightly good, 6 represent as good, and 7 represent as very good. This study used a convenience sampling technique. The survey has 
been done on nighttime weekends started from 7.30pm until 12.00 midnight.

There are three attributes in nighttime image of urban public park such as: (1) Physical setting and condition; (2) Lighting and colour; and (3) Signage and symbol. This study used indicators of a reliability scales known as internal consistency to measure the significant level of attributes. Internal consistency is the degree to which the items that make up the scale are all measuring the same underlying attribute (Pallant, 2007). Internal consistency can be measured using statistical tools from Cronbach's alpha coefficient available in the Statistical Package for the Social Sciences. This tool also provides an indication of the average correlation among all of the items of image attributes that make up the scale. Values range from 0 to 1, with higher values indicating greater reliability for this study.

\subsection{Results and Discussion}

This pilot study was developed to testify the reliability item of image of urban public park during nighttime to be used as part of domain in place identity research. Ideally, the Cronbach's alpha coefficient of scale should be above 0.7 (DeVellis, 2003). Sometimes it is difficult to get a decent Cronbach's alpha value when the item is less than 10 (Pallant, 2007). Furthermore Nunnally (1978) asserted that the value of Cronbach's alpha coefficient is 0.5 even if the items are fewer than 10. Meanwhile, according to Briggs and Cheek (1986), the item has to mention the Cronbach's alpha coefficient value together with the mean of Interitem correlation. The accepted optimal range for the mean of Inter-item correlation for this case is within range 0.20 to 0.40 . Kline (2005) stated three cases for identify reliability value; (1) good if all positive moderate to strong correlations with value of Cronbach's alpha coefficient high which is more than 0.7 ; (2) acceptable if some positive correlations; no negative correlations alpha; not awful which is more than 0.4 or 0.5 anyway; and items not noticeably different from each other; (3) problem with some negative correlations which value of Cronbach's alpha coefficient is less than -0.1 and/ or all correlations are near zero. Table 1. shows the result of summary for reliability analysis for each attribute studies which is in between 0.867 to 0.93 . Therefore the value of Cronbach's alpha coefficient for all attribute is considered reliable and significant because they are more than 0.7 . The mean of Inter item correlation which is in between 0.448 to 0.818 are also more than sufficient to support the Cronbach's alpha coefficients which need only 0.2 to 0.4 . Therefore, items of image attribute tested in this study can be used in the final studies of place identity.

Table 1. Summary of Reliability value and Mean of Inter Item Correlations

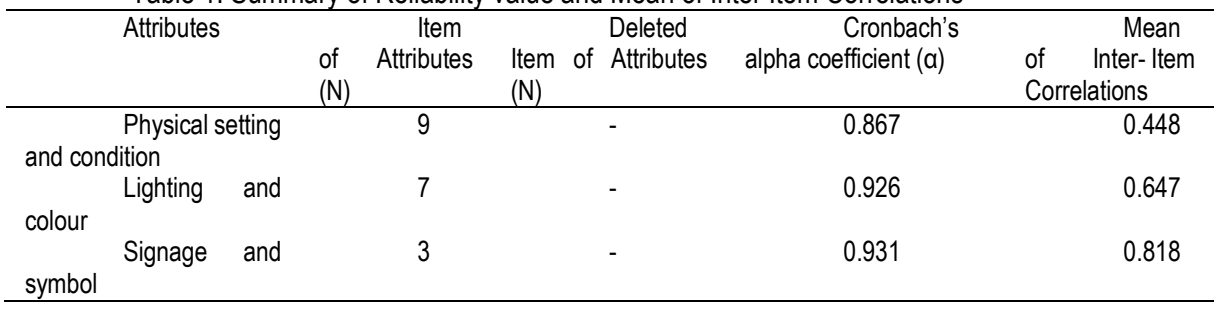




\section{Physical Setting and Condition of Urban Public Park at Night}

\begin{tabular}{ccc}
\multicolumn{2}{c}{ Table 2. Reliability value Cronbach's coefficient alpha for physical setting and condition of urban } \\
public park at night
\end{tabular}

Table 2. illustrated the 9 items for attribute of the physical setting and condition of urban park at night. Throughout the analysis, the higher value of Cronbach's Alpha (a) for this variable is (PC4) the variety of urban public park facilities which is 0.870 and the lowest is (PC8) the condition of benches which is 0.814 . There is no deleted item since all the value of Cronbach's coefficient alpha (a) items for this attribute considered as reliable because they are above 0.7 . Table 5. indicate the Inter-item correlation matrix for physical setting and condition of urban public park at night. It showed a positive correlation between items and consisting $r$ value from 0.034 to 0.845 . Meanwhile the items are not noticeably different from each other. Cheshmehzangi (2012) mentioned that, social behaviorism of a place is either controlled by design or developed with it. Therefore, environmental perception of any place has a mutual relationship with its social behaviorism termed as 'socio-environmental values' and 'spatial inter-relations'. According to Walmsley (1988), the 'environment as perceived rather than the real world which influences behaviors'. Therefore certain characteristics and urban formations are important aspects of how environment can control or/and enhance the social behaviors.

\section{Lighting and Colour of Urban Public Park at Night}

Table 3. show the 7 items for attributes of lighting and colour of urban public park at night. Throughout the analysis, the higher value of Cronbach's Alpha (a) for this variable is (LC1) the sufficient of lighting which is 0.920 and the lowest are (LC6) the colours and design of landscape plants which is 0.885 . There is no deleted item since all the value of Cronbach's coefficient alpha (a) items for this attribute considered as reliable because it is above 0.7 . Table 7. reveal the Inter-item correlation matrix for physical setting and condition of urban public park at night which showed a positive correlation between items and consisting $r$ value between 0.447 to 0.929 . In the design of urban spaces, managing light is associated with generating quality of life for its citizens. Night becomes a palette of landscapes that have 
never been seen before, transforming the landscape and image that triggers a living atmosphere of cities at night. Light can give sense to a place, giving new uses and new values (Hennessy, 2010).

Table 3. Reliability value Cronbach's coefficient alpha for lighting and colour of urban public park at night

\begin{tabular}{|c|c|c|c|}
\hline \multirow{2}{*}{ Label } & \multirow[t]{2}{*}{ Item } & \multirow[t]{2}{*}{ Item } & Cronbach's \\
\hline & & & $\begin{array}{l}\text { Coefficient Alpha (a) if } \\
\text { value item deleted }\end{array}$ \\
\hline & LC1 & Sufficient of lighting & 0.920 \\
\hline & LC2 & Brightness of lighting & 0.917 \\
\hline & LC3 & Location of lighting & 0.916 \\
\hline & LC4 & Colours of lighting & 0.914 \\
\hline & LC5 & Colours of lighting for buildings in the surrounding & 0.913 \\
\hline \multicolumn{4}{|c|}{ park area } \\
\hline & LC6 & Colours and design of landscape plants & 0.907 \\
\hline & LC7 & Colours and design of park facilities & 0.910 \\
\hline
\end{tabular}

\section{Signage and Symbol of Urban Public Park at Night}

Table 4. indicate the 3 items for attribute of signage and symbol of urban public park at night. Throughout the analysis, the higher value of Cronbach's Alpha (a) for this variable is (SS3) the naming of urban public park which is 0.925 and the lowest is (SS2) the design of signage and symbol which is 0.832 . There is no deleted item since all the value Cronbach's coefficient alpha (a) items for this attribute considered as reliable because it is above 0.7 . Table 9 . show the Inter-item correlation matrix for physical setting and condition of urban public park at night which is positive and have a strong correlation between items and consisting $r$ value between 0.732 to 0.872 . The symbolism appears in a wide range in urban design. The use of colours in designing environments and buildings is one of the significant ways in achieving symbolism. Another approach is to exploit symbolism as a notifying or informing notion. It can enhance legibility of a place and can configure the importance of individuality in the wholeness. Naming, for instance, is believed to 'connect self and identity', not in a visual form but in a symbolic manner (Ferguson, 2009). Therefore by imposing names, this influential approach in symbolism not only becomes a subjective matter but a perceptual form of the urban identity.

Table 4. Reliability value Cronbach's coefficient alpha for signage and symbol of urban public park at night

\begin{tabular}{cccc}
\hline Label & Item & Item & $\begin{array}{c}\text { Cronbach's } \\
\text { Coefficient Alpha (a) if } \\
\text { value item deleted }\end{array}$ \\
\hline & SS1 & $\begin{array}{c}\text { Clarity of signage/ symbol in relation to urban public } \\
\text { park at night }\end{array}$ & 0.918 \\
SS2 & Design of signage and symbol & 0.845 \\
SS3 & Naming of urban public park & 0.931 \\
\hline
\end{tabular}




\subsection{Conclusion}

This paper from a pilot study has been able to identify the reliability items of urban public park image in relation to its place identity during nighttime. Through the conducted survey in the case study of Shah Alam's urban public park, the image of urban public park such as physical setting and condition; lighting and colour; and signage and symbol are influenced place identity at nighttime. These findings may also influences behaviour of human leisure in urban public park during nighttime since the place and social behaviour is an inter-related element in place identity. Such evidences may contribute to new knowledge in the environmental behavior studies and help the urban designers, architectures and landscapers to create a sustainable design of public realm. Moreover, by carry out leisure in outdoor spaces during nighttime, it would rejuvenate the urban community and creating a healthy of urban lifestyle and improve the urban quality of life. Nighttime activities in public-park are part leisure and part recreation that has become an urban trend (Ngesan and Karim, 2012). As this research is confined to Shah Alam's urban public park with ample number of respondents for pilot survey, it is suggested that in the future of main survey involve adequate samples and considering urban public parks nationwide.

\section{Acknowledgement}

The writers would like to acknowledge Universiti Teknologi MARA (UiTM) and to Shah Alam City Council (MBSA) for their endless assistance given during the course of carrying out the study. This study was funded by Research Intensive Faculty (Grant 600-RMI/DANA 5/3/RIF 264/2012), provided by Research Management Institute, Universiti Teknologi MARA Shah Alam, Malaysia.

\section{References}

Briggs, S. R. \& Cheek, J. M. 1986. The role of factor analysis in the development and evaluation of personality scales. Journal of Personality, 54, 106-48.

Cheshmehzangi, A. (2012). Identity and public realm. Procedia Social and Behavioural Sciences, 50, 307-317.

Cooper, C. (1974) The House as Symbol of the Self, in J. Lang et al. (eds.) Designing for Human Behaviour: Architecture and the Behavioural Sciences (pp. 130-46). Dowden, Hutchinson and Ross, Stroudsburg.

DeVellis, R.F. (2003). Scale development: Theory and appliocation. (2nd edition). Thaousand Oaks, California, SAGE.

Ewert, A.W. (1991). Outdoor recreation and global climate change: Resource management implications for behaviours, planning, and management. Society and Natural Resouces, 4, 365- 377.

Ferguson, H. (2009) Self Identity and Everyday Life, Oxon: Routledge.

Franck, K. (1984). Exorcising the ghost of physical determinism. Environment and Behavior, 16(4), 411-435. 
Ngesan, M.R., et.al. / Asian Journal of Environment-Behaviour Studies (ajE-Bs), 3(9) Jul / Aug 2018 (p. 193-200)

Hennessy, G. (2010). Seize the night: The business and culture of new york nightlife. CreateSpace Independent Publishing Platform.

Kline, P. 1986. A handbook of test construction. New York: Methuen.

Lynch, K. (1960). The Image of the City, Cambridge: The MIT Press

Neisser, U. (1976). Cognition and Reality. San Francisco: Freeman.

Ngesan M.R. \& Karim, H.A. (2011). Impact of night commercial activities towards quality of life of urban residents. Procedia - Social and Behavioral Sciences, 35, 546 - 555.

Ngesan M.R. \& Karim, H.A. (2012). Night time social behavior in urban outdoor spaces of Shah Alam. ProcediaSocial and Behavioural Sciences, 50, 959 - 968.

Ngesan M.R. \& Karim, H.A. (2012). Human behaviour and activities in relation to Shah Alam urban park during nighttime. Procedia-Social and Behavioural Sciences, 68, 427 - 238.

Nunnally, J. 0.1978. Psychometric theory. New York:McGraw-Hill.

Oguz, D. \& Cakci, I. (2010). Changes in leisure and recreational prefrences: A case study of ankara. Scientific Research and Esseys, 5(8), 721- 729.

Pallant, J. (2007). SPSS survival manual. Allen \& Unwin.

Proshansky, H.M., \& Fabian, A.K. (1987). The quality of urban life. Walter de Gruyter \& Co. New York.

Proshansky, H.M., Fabian, A.K., \& Kaminoff, R. (1983). Place-identity: Physical world socialization of the self. Journal of Environmental Psychology, 3, 57-83.

Relph, E. (1976). Place and placelessness, London: Pion Limited.

Shaharuddin A., Noorazuan M. H, Yaakob M. J., Kadaruddin A. \& Fahmi M. (2010). The effect of different land uses on the temperature distribution in urban areas. SEAGE 2010, Hanoi 23- 26 Nov 2010. Onlice proceeding.

Thomas, S.J. (2004). Pilot Testing the Questionnaire. SAGE Research Methods.

Twigger-Ross, C.L., Bonaiuto, M., \& Breakwell, G. (2003). Identity theories and environmental psychology. Aldershot, England: Ashgate.

Walmsley, D. J. (1988). Urban living: The individual in the city, Harlow: Longman Scientific and Technical.

Wicker, A.W. (1979). An introduction to ecological psychology. Monterey, CA: Brooks/Cole.

Zaki, S.A \& Ngesan, M.R. (2012). Concept of night city: A new dimension to a city's economy. Asian Journal of Environment-Behaviour Studies, 3, 26 - 34. 